\title{
Willingness-to-try various tobacco cessation methods among US adult cigarette smokers
}

\author{
Chineme Enyioha ${ }^{1,2}$, Clare Meernik ${ }^{1,3}$, Leah Ranney ${ }^{1,3}$, Adam O. Goldstein ${ }^{1,3}$, Kathryn Sellman ${ }^{4}$, Christine E. Kistler ${ }^{1,2,3}$
}

\begin{abstract}
INTRODUCTION Long-term smoking cessation success rates without substantive intervention remain low. Some studies suggest an association between sociodemographic factors and tobacco cessation success. We explored US adult tobacco cigarette users' willingness-to-try diverse tobacco cessation methods by sociodemographics and tobacco use habits.

METHODS We electronically surveyed a convenience sample of 562 US adults to explore willingness-to-try various cessation methods among those who reported current tobacco cigarette use. Participants rated their willingness-to-try different cessation methods. Logistic regression models examined associations between willingness-to-try tobacco cessation methods based on sociodemographic and tobacco use characteristics.

RESULTS Non-Whites were more likely to report willingness-to-try counseling $(\mathrm{RR}=1.32,95 \% \mathrm{CI}: 1.14-1.52)$ and those with high school education or less were less likely to report willingness-to-try counseling ( $R R=0.78,95 \%$ CI: $0.64-$ $0.95)$. Those with lower income were less likely to report willingness-to-try any medication ( $\mathrm{RR}=0.84,95 \% \mathrm{CI}$ : $0.73-0.98)$ and any counseling $(\mathrm{RR}=0.82,95 \%$ CI: 0.67-0.99). High nicotine dependence was associated with a high likelihood of reporting willingness-to-try any evidence-based method ( $\mathrm{RR}=1.07,95 \% \mathrm{CI}$ : 1.04-1.10) and a history of quit attempts was associated with likelihood to report willingness-to-try any evidence-based method ( $\mathrm{RR}=1.31,95 \% \mathrm{CI}$ : 1.10-1.56). CONCLUSIONS Sociodemographics and nicotine dependence may affect preferences for tobacco cessation methods and should be considered when counseling patients on tobacco cessation.
\end{abstract}

\section{AFFILIATION}

1 Department of Family Medicine, School of Medicine, University of North Carolina at Chapel Hill, Chapel Hill, United States

2 The Cecil G. Sheps Center for Health Services Research, University of North Carolina at Chapel Hill, Chapel Hill, United States

3 Lineberger Comprehensive Cancer Center, University of North Carolina at Chapel Hill, Chapel Hill, United States

4 Medical College of Georgia at Augusta University, United States

\section{CORRESPONDENCE TO}

Chineme Enyioha. Department of Family Medicine, University of North Carolina, 590 Manning Drive, University of North Carolina at Chapel Hill, Chapel Hill, NC 27599, United States.

E-mail: chineme8@live.unc.edu

\section{KEYWORDS}

smoking cessation, nicotine dependence, ENDS, tobacco

Received: 15 January 2019 Revised: 12 April 2019 Accepted: 15 April 2019

\section{INTRODUCTION}

Smoking accounts for an estimated 6 million deaths every year globally. By 2030, the mortality rate is expected to increase to approximately 8 million deaths annually ${ }^{1-3}$. According to the 2016 National Health Interview Survey, up to $15.5 \%$ of adults in the US smoke cigarettes, an improvement from $20.9 \%$ in $2005^{4}$. The success rate of smoking cessation is within the range $5-7.4 \%^{5-7}$. Evidenced-based methods are less frequently used than non-evidence-based methods $^{8}$, yet studies have shown that treatment with pharmacotherapy and counseling support, either individually or when combined together, increase the likelihood of success by greater than $10 \%{ }^{9,10}$.

There is considerable variability among people who smoke, in terms of smoking cessation methods used and successful quitting ${ }^{11,12}$. In the 2010 National Health Interview Survey, low income and non-Hispanic Blacks indicated a higher interest in smoking cessation than non-Hispanic Whites but had lower rates of success ${ }^{13,14}$. In a separate study, Hispanics were half as likely to seek assistance 
with tobacco cessation compared to Whites, and heavy smokers were more likely to seek assistance compared to light smokers ${ }^{11}$. Studies have shown inconsistencies in the association between level of nicotine dependence and successful quitting ${ }^{12,15}$, and inconsistencies in the association of ENDS use and successful quitting ${ }^{12,16}$.

Gaps exist in the understanding of different subgroups of tobacco cigarette users' willingnessto-try tobacco cessation methods including counseling and pharmaceutical products ${ }^{17}$. Identifying effective strategies for tobacco cessation, integrated with patients' preferences, especially in a sociodemographically diverse setting, is beneficial and may lead to a reduction in tobacco-related morbidity and mortality ${ }^{18}$. The current study examines a convenience sample of US adult tobacco cigarette users' self-report of their willingness-to-try various forms of evidence-based and non-evidencebased cessation methods. Our study investigates whether differences in participants' preferences of tobacco cessation methods is associated with sociodemographic and tobacco use factors.

\section{METHODS}

\section{Design}

We conducted a cross-sectional online survey of various tobacco cessation methods. The study included a pretest phase using an academic email system. Twelve individuals participated in the pretesting of the survey between 9 and 14 May 2016. We revised and simplified the language of the survey based on feedback from the pretest phase. To improve the clarity of the survey, we carried out a second round of testing with 75 participants who were recruited from a survey panel via Research Now, a market research group, between 15 and 16 August 2016. After this round of testing, we revised the survey language again and fielded the final version of the survey between 26 and 31 August 2016. Participants from the Research Now panel were compensated at the marketing group's rates at the time. The UNC Chapel Hill School of Medicine Institutional Review Board approved this study.

\section{Sample}

The team enlisted and enrolled 900 participants, aged 18 years and older, who were members of an online survey panel of the Research Now market research group. The current analysis was limited to 562 participants who reported current tobacco cigarette use-defined as tobacco cigarette use in the past 30 days. Participants who reported ENDS use within the last 30 days in addition to tobacco cigarettes were also included in the study and were classified as dual users. All participants had to live in the United States and able to complete an online survey in English. Research Now does not provide data on how many people receive the initial invitation to participate in a study, thus we cannot report the response rate.

\section{Measures}

Data on sociodemographic characteristics collected included questions about race, education level and yearly household income. The survey also collected details about each participant's tobacco cigarette use characteristics including number of cigarettes per day, time to first smoke after waking, and past attempts to quit. For past quit attempts, participants were asked if they have ever tried to quit smoking tobacco cigarettes. They were not asked which method they used in the past or when they attempted to quit. The heaviness of smoking index (HSI), which estimates the level of nicotine dependence as mild, moderate or high based on the number of cigarettes smoked per day and time to first smoke after waking was calculated for each participant ${ }^{19}$.

Age was categorized into the age groups: 18-34, 35-64 and $\geq 65$ years. Some sociodemographic variables were dichotomized. Race was collapsed into non-White and White but was not further classified by ethnicity due to the low number of Hispanic participants. Education was classified as $\leq$ high school degree/GED and $\geq$ some college. Income was classified as $<\$ 30000$ and $\geq \$ 30000$. HSI was further dichotomized into high or moderate/low while quit attempts in the past year and ENDS use were categorized as yes or no. Positive responses for the use of tobacco cessation methods, i.e. 'will definitely use' and 'likely to try', were categorized as willingness-to-try for the analysis.

\section{Outcome measures}

Participants were asked to rate their willingness-to-try different forms of evidence-based and non-evidencedbased tobacco cessation methods. Response options included: 'would definitely use', 'likely to try', 'unlikely 
to try', and 'would definitely not try'. Evidence-based methods listed were medications including nicotine containing products, Wellbutrin/Zyban and Chantix, and different forms of counseling support including individual counseling, support group or class, telephone quitline, online program, texting program, and any counseling. Non-evidenced-based methods included forms of complementary and alternative therapy, other tobacco or nicotine delivery systems, and quitting without any assistance. Participants were not informed which methods are evidence-based or non-evidence-based.

\section{Analysis}

Bivariate associations between ENDS use (yes/no) and baseline characteristics (i.e. sociodemographic characteristics and tobacco use characteristics) were examined using t-tests for normally distributed continuous variables, Wilcoxon-Mann-Whitney tests for non-parametric continuous variables, and chisquared tests for categorical variables. Unadjusted and adjusted effects were estimated for willingnessto-try cessation methods using logistic regression. The cessation methods of focus were recommended methods of quitting in the form of any medication, any counseling, any evidence-based cessation method, and quitting 'cold-turkey'. 'Cold-turkey' was chosen as the independent quitting method because it is the most common method used for quit attempts. Purposeful selection method was used ${ }^{20}$ to determine variables to include in adjusted models, which involved an iterative process of examining all covariates as potential significant predictors or confounders. In the iterative process, covariates were removed from the model if they were non-significant at $\mathrm{a}=0.1$ and not a confounder (i.e. did not result in a parameter estimate change greater than 15\%). The final model included only significant covariates and confounders. Data were analyzed using SAS version 9.4 (SAS Institute, Inc.) with a two-tailed significance level $(\mathrm{p}<0.05)$. Risk ratios are reported rather than odds ratios because the outcome events are relatively common (incidence of more than $10 \%$ ) and thus risk ratios offer more appropriate approximations ${ }^{21}$.

\section{RESULTS}

From the larger sample of 900 participants who completed the survey, 562 were tobacco cigarette or dual users. Mean age was 47 years. Most participants were White $(82 \%)$, $47 \%$ were female and $76 \%$ had college education or higher. Approximately $24 \%$ of participants had an annual household income of less than $\$ 30000$. Of this sample, $88 \%$ reported smoking less than 20 cigarettes per day, $14 \%$ reported less than 5 minutes to first smoke after waking and $6.2 \%$ had a high HSI score. Eighty-three per cent reported attempting to quit smoking in the past year and almost half $(48 \%)$ were dual users (Table 1$)$.

Adjusted logistic regression analysis showed that adults in the age groups 18-34 or 35-64 years were more likely to report willingness-to-try any medication, any counseling, any evidence based method and quit 'cold-turkey' compared to adults aged $\geq 65$ years (Table 2 ). Non-White participants were more likely to report willingness-to-try any counseling method ( $\mathrm{RR}=1.32,95 \%$ CI: $1.14-1.52)$ compared to Whites, while participants with a high school education or less were less likely to

\section{Table 1. Sociodemographic characteristics $(\mathrm{N}=562)$}

$\begin{array}{lr}\text { Characteristics } & 47 \pm 20 \\ \text { Age (years) } & \\ \text { Age group (years) } & 211(38) \\ 18-34 & 148(26) \\ 35-64 & 203(36) \\ \geq 65 & \\ \text { Gender } & 263(47) \\ \text { Female } & \\ \text { Race } & 460(82) \\ \text { White } & \\ \text { Ethnicity } & 61(11) \\ \text { Hispanic or Latino } & \\ \text { Education } & 135(24) \\ \text { High school or less } & \\ \text { Annual income (US\$) } & 134(24) \\ <30000 & \\ \text { Smoking status } & 21 \pm 11 \\ \text { Days of tobacco use in past 30-day } & \\ \text { period } & \\ \geq 21 \text { cigarettes/day } & 67(12) \\ \text { History of quit attempts } & 466(83) \\ \text { Current ENDS use } & 269(48) \\ \text { Minutes to first smoke after waking } & \\ \leq 5 & \\ 6-30 & \\ 31-60 & \\ >60 & \\ & \\ & \\ & \end{array}$

SD: standard deviation 
report willingness-to-try any counseling method compared to those with a college education or higher ( $R R=0.78,95 \%$ CI: 0.64-0.95). Participants with an annual income of less than $\$ 30000$ were less likely to report willingness-to-try any medication $(\mathrm{RR}=0.84$, 95\% CI: $0.73-0.98)$ and any counseling $(\mathrm{RR}=0.82$, 95\% CI: 0.67-0.99) compared to participants with higher annual income.

Participants with a high HSI score were more likely to report willingness-to-try any medication, any counseling and any evidenced-based method $(\mathrm{RR}=1.07,95 \% \mathrm{CI}: 1.04-1.10)$ and less likely to report willingness-to-try 'cold-turkey' $(\mathrm{RR}=0.90$, 95\% CI: 0.87-0.94). Those who had attempted to quit in the past were also more likely to report willingness-to-try any medication, any counseling and any evidenced-based method ( $\mathrm{RR}=1.31,95 \%$ CI: 1.10-1.56) compared to those with no history of quit attempts. Although dual users were more likely to report willingness-to-try any counseling and any evidenced-based method compared to tobacco cigarette only users, these associations lost statistical significance after adjusting for other variables in the final model (Table 2).

Table 3 represents a breakdown of comparison of willingness-to-try different tobacco cessation methods among tobacco cigarette-only users and dual users. Dual users were more likely to report a willingness-to-try Wellbutrin compared to tobaccoonly users with similar non-significant trends for other medications ( $41 \%$ vs $30 \%$; $p=0.005$ ). Dual users were significantly more likely to report willingnessto-try any type of counseling support listed, except for individual counseling, which did not reach statistical significance. Overall, dual users were more likely to report a willingness-to-try any evidencebased method compared to tobacco cigarette only users $(82 \%$ vs $73 \%$; $=0.01)$. Dual users were also more likely to report willingness-to-try nonevidenced-based methods including different forms of complementary and alternative methods and other tobacco or nicotine delivery systems.

Table 2. Association between baseline characteristics and willingness-to-try cessation methods among tobacco cigarette users $(\mathrm{N}=562)$

\begin{tabular}{|c|c|c|c|c|}
\hline \multirow[b]{3}{*}{ Baseline Characteristics } & \multicolumn{4}{|c|}{ Willingness to try } \\
\hline & Any medication & Any counseling & $\begin{array}{l}\text { Any evidence based } \\
\text { method }\end{array}$ & 'Cold turkey' \\
\hline & $\operatorname{ARR}(95 \% \mathrm{CI})$ & $\operatorname{ARR}\left(95^{\circ} \mathrm{CI}\right)$ & $\operatorname{ARR}\left(95^{\circ} \% \mathrm{CI}\right)$ & $\operatorname{ARR}\left(95^{\circ} \% \mathrm{CI}\right)$ \\
\hline \multicolumn{5}{|l|}{ Ages (years) } \\
\hline $18-34$ vs $\geq 65$ & $1.15(1.00-1.32)$ & $1.84(1.05-3.24)$ & $1.16(1.03-1.31)$ & $1.33(1.15-1.54)$ \\
\hline \multicolumn{5}{|l|}{ Ages } \\
\hline $35-64$ vs $\geq 65$ & $1.14(1.00-1.29)$ & $1.44(1.07-1.93)$ & $1.14(1.02-1.27)$ & $1.31(1.12-1.53)$ \\
\hline \multicolumn{5}{|l|}{ Gender } \\
\hline Female vs Male & - & - & $1.07(0.98-1.17)$ & - \\
\hline \multicolumn{5}{|l|}{ Race } \\
\hline non-White vs White & - & $1.32(1.14-1.52)$ & - & $1.00(0.88-1.14)$ \\
\hline \multicolumn{5}{|l|}{ Ethnicity } \\
\hline Hispanic Yes vs No & - & - & - & $0.96(0.83-1.13)$ \\
\hline \multicolumn{5}{|l|}{ Education } \\
\hline$\leq \mathrm{HS}$ vs $\geq$ some College & - & $0.78(0.64-0.95)$ & $0.94(0.84-1.05)$ & - \\
\hline \multicolumn{5}{|c|}{ Annual household income (US\$) } \\
\hline$<30000$ vs $\geq 30000$ & $0.84(0.73-0.98)$ & $0.82(0.67-0.99)$ & $0.92(0.82-1.03)$ & - \\
\hline \multicolumn{5}{|l|}{ HSI score } \\
\hline High vs Low/Medium & $1.11(1.07-1.15)$ & $1.06(1.02-1.12)$ & $1.07(1.04-1.10)$ & $0.90(0.87-0.94)$ \\
\hline \multicolumn{5}{|l|}{ Ever tried to quit } \\
\hline Yes vs No & $1.30(1.06-1.58)$ & $1.36(1.07-1.72)$ & $1.31(1.10-1.56)$ & $1.15(0.97-1.35)$ \\
\hline \multicolumn{5}{|l|}{ Current ENDS use } \\
\hline Yes vs No & - & - & 1.05 (0.95-1.14) & - \\
\hline
\end{tabular}

ARR: adjusted risk ratio. HSI: Heaviness Smoking Index. 
Table 3. Willingness-to-try tobacco cessation methods, n (\%)

\begin{tabular}{|c|c|c|c|c|}
\hline Tobaceo Cessation Vethods & Total $(\mathrm{N}=562)$ & $\begin{array}{l}\text { Current tobaceo } \\
\text { cigarette only } \\
\text { users (n-293) }\end{array}$ & $\begin{array}{l}\text { Current tobacco } \\
\text { cigarette and ENDS } \\
\text { users (n-269) }\end{array}$ & $p$ \\
\hline \multicolumn{5}{|l|}{ Evidence Based Methods } \\
\hline \multicolumn{5}{|l|}{ Medications } \\
\hline Nicotine containing products & $329(58)$ & $161(55)$ & $168(62)$ & 0.07 \\
\hline Wellbutrin/Zyban (Bupropion) & $197(35)$ & 87 (29) & $110(41)$ & 0.005 \\
\hline Chantix (Varenicline) & 222 (39) & $107(36)$ & $115(43)$ & 0.13 \\
\hline Any medication & $388(69)$ & $194(66)$ & $194(72)$ & 0.13 \\
\hline \multicolumn{5}{|l|}{ Counseling support } \\
\hline Individual counseling & $221(39)$ & $106(36)$ & $115(43)$ & 0.11 \\
\hline Support group/group class & $185(33)$ & 80 (27) & 105 (39) & 0.003 \\
\hline Telephone quitline & $147(26)$ & $61(21)$ & $86(32)$ & 0.003 \\
\hline Online program & $220(39)$ & $98(33)$ & $122(45)$ & 0.004 \\
\hline Texting program & $145(26)$ & $60(20)$ & 85 (32) & 0.003 \\
\hline Any counseling support & $320(57)$ & $154(53)$ & $166(62)$ & 0.03 \\
\hline Any evidence-based method (medication or counseling) & $434(77)$ & $214(73)$ & $220(82)$ & 0.01 \\
\hline \multicolumn{5}{|l|}{ Von Evidence Based Alternative Vethods } \\
\hline \multicolumn{5}{|l|}{ Complementary and Alternative Methods } \\
\hline Mindfulness therapy/meditation & $269(48)$ & $121(41)$ & $148(55)$ & 0.001 \\
\hline Hypnosis & $256(46)$ & $119(41)$ & $137(51)$ & 0.01 \\
\hline Acupuncture & $241(43)$ & 114 (39) & $127(47)$ & 0.05 \\
\hline Any complementary and alternative method & $357(63)$ & $171(58)$ & $186(69)$ & 0.008 \\
\hline \multicolumn{5}{|l|}{ Other Tobacco or Nicotine Delivery Systems } \\
\hline Smokeless tobacco & $121(21)$ & $28(10)$ & $93(35)$ & $<0.0001$ \\
\hline $\begin{array}{l}\text { Electronic vaping devices (e-cigarettes, e-hookahs, } \\
\text { vape pens, e-pens) }\end{array}$ & $402(71)$ & $164(56)$ & $238(88)$ & $<0.0001$ \\
\hline Any other tobacco or nicotine delivery system & $410(73)$ & $167(57)$ & $243(90)$ & $<0.0001$ \\
\hline \multicolumn{5}{|l|}{ Quit on My Own } \\
\hline 'Cold-turkey' (pick a date and quit) & $385(68)$ & $191(65)$ & $194(72)$ & 0.07 \\
\hline Cutting back gradually & $467(83)$ & $233(79)$ & $234(87)$ & 0.02 \\
\hline Any independent quitting method & $511(91)$ & $262(89)$ & 249 (93) & 0.19 \\
\hline
\end{tabular}

\section{DISCUSSION}

The current study explores a convenience sample of tobacco users' willingness-to-try different tobacco cessation methods by sociodemographics and level of nicotine dependence. Our findings reveal that preferences for tobacco cessation methods exist based on race/ethnicity, level of income, education and severity of nicotine dependence. While nonWhite participants were significantly more likely to report willingness-to-try counseling over other cessation methods, those with lower education level were less likely to report willingness-to-try counseling and those with an annual household income of less than $\$ 30000$ were less likely to report willingnessto-try any medication. Participants with a higher HSI, i.e. higher tobacco dependency, were more likely to report willingness-to-try any evidence-based cessation method over non-evidence-based methods. The data also indicate that dual users were more likely to report willingness-to-try any evidenced-based method compared to tobacco cigarette-only users.

Our results have implications for public health practice, primary care clinician counseling services and for future research. We found that young and middle-aged adults were more likely to report willingness-to-try any medication, any counseling, any evidence-based method and quit "coldturkey' compared to adults aged $\geq 65$ years. This is inconsistent with some findings in the literature. One study showed that older adults are more likely to use counseling than young and middle-aged adults, but are less likely to be prescribed nicotine replacement 
therapy ${ }^{22}$, which may explain the low likelihood of willingness-to-try any medication found in our study. Older adults may also be concerned about side effects of nicotine replacement therapy and other smoking cessation medications ${ }^{23}$. Another study found that both the old and young adults are less likely to use pharmacotherapy and less likely to use evidence-based methods but more likely to use substitutes such as ENDS products. Young adults, however, are less likely to use evidence-based methods compared to old adults, which may be due to the high level of confidence they have that they can quit without assistance or concerns about the effectiveness of evidence-based methods ${ }^{24}$.

Our finding that non-White participants had a higher likelihood to report willingness-to-try counseling compared to Whites is similar to previous studies that showed a higher utilization of quitlines and telephone counseling by non-Whites compared to White tobacco users in studies that assessed variations in quitline reach by ethnicity and race $^{25,26}$. This preference for counseling over other methods may arise from lack of knowledge or awareness about pharmacological therapies, their perceived costs, harms or their effectiveness, leading to a perceived preference for counseling. Some studies have shown that, compared to White tobacco users, non-Whites are less likely to be screened for tobacco use or advised to quit by a healthcare provider ${ }^{27,28}$ and hence, may not be aware of all their options. Another study to assess ethnic minority group's beliefs and perspectives for recommended treatment options for tobacco cessation found that many participants were not fully aware that medications are beneficial and were concerned about risks of side effects ${ }^{29}$. These concerns may have contributed to findings in the current study and may explain why non-Whites reported willingness-to-try counseling over other methods.

We found that participants with an annual income less than $\$ 30000$ were less likely to report willingness-to-try any medication and counseling. This finding may be related to costs especially for low-income smokers who may be uninsured. While the daily cost of cessation medications, for example, may be similar to the cost of cigarettes, these medications tend to come in weekly or monthly supply, making it unaffordable for low-income smokers who may need to pay out-of-pocket ${ }^{30}$, especially for low-income patients ${ }^{31}$. This association has been mentioned in other studies that showed that low-income patients with chronic disease cut back on essential medications or are non-adherent due to $\operatorname{cost}^{32,33}$. Removal of the cost barrier or the offer of free treatment may increase preference and hence use of pharmacotherapy for tobacco cessation among low-income patients ${ }^{34}$. An annual household income of less than $\$ 30000$ was also associated with a lower likelihood of reporting willingness-totry any counseling. Although one might expect that the lower cost of counseling makes it an attractive cessation method for low-income smokers, studies have shown the opposite ${ }^{35}$. Elements such as distrust and lack of knowledge have been cited as reasons for the low utilization of counseling among lowincome smokers ${ }^{36,37}$. Other challenges such as access to healthcare settings that can also provide smoking cessation services including counseling, health issues related to depression and substance or alcohol abuse, in addition to daily challenges, may make counseling for smoking cessation less attractive to low-income smokers $^{38}$.

Although we found that participants with lower levels of education were less likely to indicate a willingness-to-try any counseling, other studies have shown mixed results, indicating a positive, negative or non-significant association between low education and participation in counseling ${ }^{11,39-41}$. Our findings may be a result of the fact that people with low educational status are less likely to receive smoking cessation advice ${ }^{28,42}$ and hence may not be aware of counseling as an option.

Tobacco use characteristics seem to play a role in willingness-to-try different cessation methods. Participants with a high level of nicotine dependence were more likely to report a willingness-to-try any evidence-based method and less likely to report willingness-to-try to quit 'cold-turkey'. This is similar to findings by Zhu et al. ${ }^{11}$ who found that heavy smokers were twice as likely to seek assistance as light smokers. In this study, the assistance involved both evidence-based and non-evidencedbased methods such as self-help materials. The fact that those with high level of nicotine dependence are less likely to quit 'cold-turkey' may stem from previous failed attempts to quit without assistance 
or concerns that the severity of their nicotine dependence may make it challenging to quit independently.

In addition, participants with a history of previous quit attempts were more likely to report willingnessto-try any evidence-based method. A similar study that assessed preferences for future quit attempts showed that a history of previous quit attempts with medications was associated with interest in pharmacotherapy for future quit attempts ${ }^{43}$. Another study showed that smokers tend to use the same cessation methods that they tried at their baseline quit attempt ${ }^{44}$. It is unclear if participants in our study reported willingness-to-try evidencebased methods based on cessation methods used in previous quit attempts.

Our study also showed that dual users were more willing to report a willingness-to-try both evidence and non-evidenced-based methods compared to tobacco cigarette-only users. The significant difference noted between the two groups suggests that dual users are willing to try any method in an attempt to stop smoking. However, after adjusting for other sociodemographic and tobacco use variables, no statistically significant difference was found. This suggests that other characteristics involved, such as their tobacco use habits, may have a stronger influence than dual-use and affect their likelihood to use certain methods over others. Furthermore, findings from various studies have shown that ENDS users are likely to attempt to quit overall ${ }^{45,46}$, and for some, ENDS use may be their cessation method of choice ${ }^{47}$.

\section{Limitations}

Limitations of this study include its cross-sectional design and restriction to those able to complete an online survey. Since the study was on volunteer participants, the findings may not be applicable to the general population. The cross-sectional nature also limits the ability to explore causality and to capture other factors that may affect responses of participants. Participants were not asked about their knowledge of smoking cessation methods and may not have been aware of all methods or their efficacy, which may have affected their report of willingness-to-try different methods. Another limitation is the reliance of self-reported information about smoking status and habit, which may not reflect true characteristics.
Our findings reflect participants' willingness-to-try different methods and may not correlate with actual choices. Responses to questions may also have been affected by participants' recall bias. The level of nicotine dependence was measured by the heaviness of smoking index (HSI), which is a validated tool for measuring dependence on cigarette smoking. Hence, findings of this study may not be applicable to users of other combustible tobacco or non-combustible products. The association between the different sociodemographic groups and the willingness-to-try different cessation methods was limited to evidencebased methods and the most common independent quit method. ENDS and other cessation methods were not included in the analysis of sociodemographics and willingness-to-try different cessation methods. Furthermore, we were unable to analyze for differences between minority race and ethnicities due to the limited number of non-White or Hispanic individuals in our sample.

\section{CONCLUSIONS}

Despite improvement in the availability of interventions for smoking cessation, success rate is still suboptimal. To close this gap, efforts have been made to increase access to evidence-based methods of cessation but some methods remain preferred over others. Findings of this study highlight preferred methods for smoking cessation based on sociodemographics and level of nicotine dependence. The implication is that medical providers and those involved in the provision of tobacco cessation programs need to be mindful that individuals can differ in their preference for a smoking cessation method based on factors such as sociodemographics and nicotine dependence. In addition, increased education on evidenced-based tobacco cessation methods for smokers trying to quit will be beneficial. Further studies to evaluate methods actually used by former tobacco users of different sociodemographics and level of nicotine dependence will be helpful and may aid in the development of targeted therapies for patients to increase the likelihood of success in their smoking cessation efforts.

\section{REFERENCES}

1. Mathers CD, Loncar D. Projections of global mortality and burden of disease from 2002 to 2030 . 
Samet J, ed. PLoS Medicine. 2006;3(11):e442. doi:10.1371/journal.pmed.0030442

2. Inoue-Choi M, Liao LM, Reyes-Guzman C, Hartge P, Caporaso N, Freedman ND. Association of long-term, low-Intensity smoking with all-cause and cause-specific mortality in the National Institutes of Health-AARP Diet and Health Study. JAMA Intern Med. 2017;177(1):87-95. doi:10.1001/jamainternmed.2016.7511

3. World Health Organization. WHO Global Report: Mortality attributable to tobacco, 2012. Accessed June 15, 2017.

4. Jamal A, Phillips E, Gentzke AS, et al. Current Cigarette Smoking Among Adults - United States, 2016. Morbidity and Mortality Weekly Report. 2018;67(2):5359. doi:10.15585/mmwr.mm6702a1

5. Jacquart J, Papini S, Davis ML, et al. Identifying attendance patterns in a smoking cessation treatment and their relationships with quit success. Drug Alcohol Depend. 2017;174:65-69. doi:10.1016/j.drugalcdep.2017.01.007

6. Babb S, Malarcher A, Schauer G, Asman K, Jamal A. Quitting smoking among adults — United States, 20002015. MMWR Morb Mortal Wkly Rep. 2017;65:14571464. doi: 10.15585/mmwr.mm6552a1

7. Joly B, Perriot J, d'Athis P, Chazard E, Brousse G, Quantin C. Success rates in smoking cessation: Psychological preparation plays a critical role and interacts with other factors such as psychoactive substances. Pershouse MA, ed. PLoS ONE. 2017;12(10):e0184800. doi:10.1371/ journal.pone.0184800

8. Caraballo RS, Shafer PR, Patel D, Davis KC, McAfee TA. Quit methods used by US adult cigarette smokers, 2014-2016. Prev Chronic Dis. 2017;14:160600. doi:10.5888/pcd14.160600

9. Ranney L, Melvin C, Lux L, McClain E, Lohr KN. Systematic review: Smoking cessation intervention strategies for adults and adults in special populations. Ann Intern Med. 2006;145:845-856. doi:10.7326/0003-4819-145-11-200612050-00142

10. Cokkinides VE, Ward E, Jemal A, Thun MJ. Underuse of smoking-cessation treatments: results from the National Health Interview Survey, 2000. Am J Prev Med 2005;28:119-22. doi:10.1016/j.amepre.2004.09.007

11. Zhu S, Melcer T, Sun J, Rosbrook B, Pierce JP. Smoking cessation with and without assistance: a population based analysis. Am J Prev Med. 2000;18(4):305-311. doi:10.1016/s0749-3797(00)00124-0

12. El-Khoury Lesueur F, Bolze C, Melchior M. Factors associated with successful vs. unsuccessful smoking cessation: Data from a nationally representative study. Addict Behav. 2018;80:110-115. doi:10.1016/j.addbeh.2018.01.016

13. Centers for Disease Control and Prevention (CDC). Quitting smoking among adults-United States, 2001-2010. MMWR MMWR Morb Mortal Wkly Rep. 2011;60:1513-19.

14. King G, Polednak A, Bendel RB, Vilsaint MC, Nahata
SB. Disparities in smoking cessation between African Americans and Whites: 1990-2000. Am J Public Health. 2004;94(11):1965-1971. doi:10.2105/ajph.94.11.1965

15. Vangeli E, Stapleton J, Smit ES, Borland R, West R. Predictors of attempts to stop smoking and their success in adult general population samples: a systematic review. Addiction. 2011;106(12):2110-2121. doi:10.1111/j.1360-0443.2011.03565.x

16. Brown J, Beard E, Kotz D, Michie S, Wes, R. Real-world effectiveness of e-cigarettes when used to aid smoking cessation: a cross-sectional population study. Addiction. 2014;109(9):1531-1540. doi:10.1111/add.12623

17. Fagan P, King G, Lawrence D, et al. Eliminating tobacco-related health disparities: Directions for future research. Am J Public Health. 2004;94(2):211-217. doi:10.2105/ajph.94.2.211

18. Onor IO, Stirling DL, Williams SR, et al. Clinical effects of cigarette smoking: epidemiologic impact and review of pharmacotherapy options. Int J Environ Res Public Health. 2017;14(10):1147. doi:10.3390/ijerph14101147.

19. Heatherton TF, Kozlowski LT, Frecker RC, Rickert W. Robinson J. Measuring the Heaviness of Smoking: using self-reported time to the first cigarette of the day and number of cigarettes smoked per day. Br J Addict. 1989;84(7):791799. doi:10.1111/j.1360-0443.1989.tb03059.x

20. Bursac Z, Gauss CH, Williams DK, Hosmer DW. Purposeful selection of variables in logistic regression. Source Code Biol Med. 2008;3:17. doi:10.1186/1751-0473-3-17.

21. Spiegelman D, Hertzmark E. Easy SAS calculations for risk or prevalence ratios and differences, Am J Epidemiol, 2005;162(3):199-200. doi:10.1093/aje/kwi188

22. Jordan H, Hidajat M, Payne N, Adams J, White M, Ben-Shlomo Y. What are older smokers' attitudes to quitting and how are they managed in primary care? An analysis of the cross-sectional English Smoking Toolkit Study. BMJ Open. 2017;7(11):e018150. doi:10.1136/bmjopen-2017-018150

23. Ryan MP, Hinojosa JJ. Conceptual obstacles to making use of four smoking-cessation strategies: what reasons do light smokers give for rejecting strategies? Health Psychol Open . 2015;2(2):1-2. doi:10.1177/2055102915624928

24. Watkins LS, Thrul J, Max W, Ling PM; Cold Turkey and Hot Vapes? A National Study of Young Adult Cigarette Cessation Strategies, Nicotine \& Tobacco Research, doi:10.1093/ntr/nty270

25. Rabius V, Wiatrek D, McAlister AL. African American participation and success in telephone counseling for smoking cessation. Nicotine Tob Res. 2012;14(2):240242.doi:10.1093/ntr/ntr129

26. Zhu SH, Gardiner P, Cummins S, et al. Quitline utilization rates of African-American and white smokers: The California experience. Am J Health Promot. 2011;25(5 suppl):S51-S58. doi:10.4278/ajhp.100611-quan-185

27. Cokkinides VE, Halpern MT, Barbeau EM, Ward E, Thun MJ. Racial and ethnic disparities in smoking-cessation 
intervention: Analysis of the 2005 National Health Interview Survey. Am J of Prev Med. 2008;34(5):404412. doi:10.1016/j.amepre.2008.02.003

28. Houston TK, Scarinci IC, Person SD, Greene PG. Patient smoking cessation advice by health care providers: The role of ethnicity, socioeconomic status, and health. Am J Public Health. 2005;95(6):1056-1061. doi:10.2105/AJPH.2004.039909

29. Fu SS, Burgess D, van Ryn M, Hatsukami DK, Solomon J. Joseph AM. Views on smoking cessation methods in ethnic minority communities: a qualitative investigation. Prev Med. 2007;44(3):235-240. doi:10.1016/j.ypmed.2006.11.002

30. Karadoğan D, Önal Ö, Kanbay Y. How does reimbursement status affect smoking cessation interventions? A reallife experience from the Eastern Black Sea region of Turkey. Tob. Induc. Dis. 2019;17(January). doi:10.18332/tid/100412.

31. Gollust SE, Schroeder SA, Warner KE. Helping smokers quit: Understanding the barriers to utilization of smoking cessation services. Milbank Q. 2008;86(4):601-627. doi:10.1111/j.1468-0009.2008.00536.x

32. Ngo-Metzger Q, Sorkin DH, Billimek J, Greenfield $\mathrm{S}$, Kaplan SH. The effects of financial pressures on adherence and glucose control among racial/ethnically diverse patients with diabetes. J Gen Intern Med. 2012;27(4):432-437. doi:10.1007/s11606-011-1910-7

33. Wagner TH, Heisler M, Piette JD. Prescription drug co-payments and cost-related medication underuse. Health Econ, Policy Law. 2008;3(1):51-67. doi:10.1017/s1744133107004380

34. Cupertino AP, Richter KP, Sanderson Cox L, et al. Smoking cessation pharmacotherapy preferences in rural primary care. Nicotine Tob Research :official journal of the Society for Research on Nicotine and Tobacco. 2008;10(2):301. doi:10.1080/14622200701825817.

35. Siahpush M, Wakefield M, Spittal M, Durkin S. Antismoking television advertising and socioeconomic variations in calls to Quitline. J Epidemiol Community Health. 2007;61(4):298-301. doi:10.1136/jech.2005.043380

36. Sheffer CE, Brackman SL, Cottoms N, Olsen M. Understanding the barriers to use of free, proactive telephone counseling for tobacco dependence. Qual Health Res. 2011;21(8):1075-1085. doi:10.1177/1049732311404248

37. Sheffer C, Brackman S, Lercara C, et al. When Free Is Not for Me: Confronting the Barriers to Use of Free Quitline Telephone Counseling for Tobacco Dependence. Int J Environ Res Public Health. 2015;13(1):15. doi:10.3390/ijerph13010015

38. Bock BC, Papandonatos GD, de Dios MA, et al. Tobacco cessation among low-income smokers: motivational enhancement and nicotine patch treatment. Nicotine Tob Res. 2013;16(4):413-422. doi:10.1093/ntr/ntt166

39. Wen KY, Miller SM, Lazev A, Fang Z, Hernandez E. Predictors of smoking cessation counseling adherence in a socioeconomically disadvantaged sample of pregnant women. J health care poor underserved. 2012;23(3):1222-1238. doi:10.1353/hpu.2012.0096

40. Choo EK, Sullivan AF, LoVecchio F, Perret JN, Camargo CA, Boudreaux ED. Patient preferences for emergency department-initiated tobacco interventions: a multicenter cross-sectional study of current smokers. Addict Sci Clin Pract. 2012;7(1):4. doi:10.1186/1940-0640-7-4

41. Maher JE, Rohde K, Dent CW, Stark MJ, Pizacani B, Boysun MJ. et al. Is a statewide tobacco quitline an appropriate service for specific populations? Tob Control. 2007;16(Suppl 1):i65-i70. doi:10.1136/tc.2006.019786

42. Lee DJ, Fleming LE, McCollister KE, et al. Healthcare provider smoking cessation advice among US worker groups. Tob Control. 2007;16(5):325-328. doi:10.1136/tc.2006.019117

43. Thomas D, Abramson MJ, Bonevski B, et al. Quitting experiences and preferences for a future quit attempt: a study among inpatient smokers. BMJ Open. 2015;5(4):e006959. doi:10.1136/bmjopen-2014-006959

44. Ferguson SG, Brown J, Frandsen M, West R. Association between use of pharmacological aids in a smoking cessation attempt and subsequent quitting activity: a population study. Addiction. 2015;110(3):513-518. doi:10.1111/add.12795

45. Berry KM, Reynolds LM, Collins JM, et al. E-cigarette initiation and associated changes in smoking cessation and reduction: the Population Assessment of Tobacco and Health Study, 2013-2015. Tob Control. 2018. doi:10.1136/tobaccocontrol-2017-054108

46. Zhu SH, Zhuang YL, Wong S, Cummins SE, Tedeschi GJ. E-cigarette use and associated changes in population smoking cessation: evidence from US current population surveys. The BMJ. 2017;358:j3262. doi:10.1136/bmj.j3262

47. Vickerman KA, Schauer GL, Malarcher AM, Zhang L, Mowery P, Nash CM. Reasons for electronic nicotine delivery system use and smoking abstinence at 6 months: A descriptive study of callers to employer and health plan-sponsored quitlines. Tob Control. 2017;26(2):126. doi:10.1136/tobaccocontrol-2015-052734

\section{ACKNOWLEDGEMENTS}

T. Crutchfield is acknowledged for her assistance as the project manager.

\section{CONFLICTS OF INTEREST}

A.O. Goldstein reports other from Pfizer Advisory Board, outside the submitted work. The rest of the authors have also completed and submitted an ICMJE form for disclosure of potential conflicts of interest and none was reported.

\section{FUNDING}

This work was supported in part by the University of North Carolina at Chapel Hill University Cancer Research Fund at the Lineberger Comprehensive Cancer Center and UNC Primary Care Research Fellowship.

PROVENANCE AND PEER REVIEW

Not commissioned; externally peer reviewed. 